\title{
REVISED Bio-electrosprayed human neural stem cells are viable and maintain their differentiation potential [version 2; peer
}

\section{review: 3 approved]}

\author{
Citlali Helenes González¹, Suwan N. Jayasinghe², Patrizia Ferretti (iD)1 \\ ${ }^{1}$ Stem Cell and Regenerative Medicine Section, UCL Great Ormond Street Institute of Child Health, University College London, \\ London, WC1N 1EH, UK \\ ${ }^{2}$ BioPhysics Group, Department of Mechanical Engineering, University College London, London, WC1E 7JE, UK
}

\author{
V2 First published: 17 Apr 2020, 9:267 \\ https://doi.org/10.12688/f1000research.19901.1 \\ Latest published: $31 \mathrm{Jul}$ 2020, 9:267 \\ https://doi.org/10.12688/f1000research.19901.2
}

\section{Abstract}

Background: Bio-electrospray (BES) is a jet-based delivery system driven by an electric field that has the ability to form micro to nanosized droplets. It holds great potential as a tissue engineering tool as it can be used to place cells into specific patterns. As the human central nervous system (CNS) cannot be studied in vivo at the cellular and molecular level, in vitro CNS models are needed. Human neural stem cells (hNSCs) are the CNS building block as they can generate both neurones and glial cells.

Methods: Here we assessed for the first time how hNSCs respond to BES. To this purpose, different hNSC lines were sprayed at $10 \mathrm{kV}$ and their ability to survive, grow and differentiate was assessed at different time points.

Results: BES induced only a small and transient decrease in hNSC metabolic activity, from which the cells recovered by day 6 , and no significant increase in cell death was observed, as assessed by flow cytometry. Furthermore, bio-electrosprayed hNSCs differentiated as efficiently as controls into neurones, astrocytes and oligodendrocytes, as shown by morphological, protein and gene expression analysis. Conclusions: This study highlights the robustness of hNSCs and identifies BES as a suitable technology that could be developed for the direct deposition of these cells in specific locations and configurations.

Keywords

bio-electrospray, death, differentiation, human, in vitro, neural stem cells, neurone, survival

\section{A.}

This article is included in the UCL Child Health gateway.

\section{Open Peer Review \\ Approval Status \\ 1 \\ 2 \\ 3 \\ version 2 \\ (revision) \\ $\checkmark$ \\ view

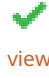 \\ 17 Apr 2020 \\ 1. Jamie A. Davies (D), University of Edinburgh, Edinburgh, UK \\ 2. Jingwei Xie (D), University of Nebraska \\ Medical Center, Omaha, USA \\ 3. Patricia Pranke ID, Universidade Federal do Rio Grande do Sul (UFRGS), Porto Alegre, \\ Brazil}

Any reports and responses or comments on the article can be found at the end of the article. 
Corresponding authors: Citlali Helenes González (citlali.gonzalez.12@ucl.ac.uk), Patrizia Ferretti (p.ferretti@ucl.ac.uk)

Author roles: Helenes González C: Conceptualization, Data Curation, Formal Analysis, Funding Acquisition, Investigation, Methodology, Visualization, Writing - Original Draft Preparation; Jayasinghe SN: Conceptualization, Resources, Writing - Review \& Editing; Ferretti P: Conceptualization, Funding Acquisition, Project Administration, Supervision, Writing - Review \& Editing

Competing interests: No competing interests were disclosed.

Grant information: This work was supported by a CONACYT Graduate Fellowship (Fellow No. 217404) to CHG and the National Institute for Health Research (NIHR) Biomedical Research Centre Great Ormond Street Biomedical Research Centre (GOSH BRC). The human embryonic and foetal material was provided by the Human Developmental Biology Resource (http://hdbr.org), jointly funded by the Medical Research Council (grant G070089) and The Wellcome Trust (grant GR082557).

The funders had no role in study design, data collection and analysis, decision to publish, or preparation of the manuscript.

Copyright: (c) 2020 Helenes González C et al. This is an open access article distributed under the terms of the Creative Commons Attribution License, which permits unrestricted use, distribution, and reproduction in any medium, provided the original work is properly cited.

How to cite this article: Helenes González C, Jayasinghe SN and Ferretti P. Bio-electrosprayed human neural stem cells are viable and maintain their differentiation potential [version 2; peer review: 3 approved] F1000Research 2020, 9:267

https://doi.org/10.12688/f1000research.19901.2

First published: 17 Apr 2020, 9:267 https://doi.org/10.12688/f1000research.19901.1 


\section{REVISED Amendments from Version 1}

In response to peer review comments, we have included the catalogue numbers of the biologics used (full information for some reagents was inaccessible due to Covid-19 lockdown controls), clarified that the needle used was a standard straight cut hypodermic needle made of stainless steel. We have also included the field strength, added a new reference and made minor edits to the text.

Any further responses from the reviewers can be found at the end of the article

\section{Introduction}

Electrospraying is a very useful technique for fabricating micro- and nano-structures of different composition, texture and shape using a wide range of materials and cells. When cells are electrosprayed, the technique is known as bio-electrospray (BES). BES consists of a jet-based delivery system connected to an electric field that has the ability to generate nano-sized and cell-laden microdroplets (Jayasinghe, 2011; Jayasinghe \& Townsend-Nicholson, 2006; Poncelet et al., 2012). This is due to the difference in electric potential between the charged needle and the ground electrode that forms an electric field, accelerating the charged cell suspension within the needle and forming an unstable jet. This methodology has the advantage of having the potential to achieve single-cell delivery, giving a more homogeneous cell distribution within a 3-dimensional (3D) construct, as well as being very suitable for microencapsulation (Boda et al., 2018; Jayasinghe, 2011; Poncelet et al., 2012). The configuration needed to obtain micro to nano-sized droplets and a near monodistribution can be achieved by adjusting BES conditions to obtain a stable cone jet mode. The primary conditions to consider are viscosity and electrical conductivity of the sprayed liquid. Ideally, the cell-laden suspension should have high viscosity and low electrical conductivity. A coaxial arrangement with an outer needle carrying an encapsulating biomaterial and an inner needle carrying the cells in suspension could also be considered (Jayasinghe et al., 2006; Jayasinghe \& Townsend-Nicholson, 2006). Other strategies adopted to obtain such a high resolution require small diameter needles, resulting in shear stress to the cells and an inability to process high-density and/or viscous cell suspensions (Greig \& Jayasinghe, 2008; Hall et al., 2008).

An important consideration for cell-based applications is that the high voltages and spraying action could have an adverse effect on the cells, and this may differ among cell types. Although it has been demonstrated that BES does not significantly affect a range of mammalian cells, and even small organisms, its effect have never been studied on human neural stem cells (hNSCs), the building block of the nervous system (Clarke \& Jayasinghe, 2008; Geach et al., 2009; Hong et al., 2010; Jayasinghe et al., 2011; Joly et al., 2009; Tezera et al., 2017).

hNSCs either derived from the embryonic nervous system or differentiated from pluripotent stem cells provide an ideal source for modelling the human nervous system. hNSCs have the capacity to self-renew and differentiate into the major cell types of the brain, neurones and glia (oligodendrocytes and astrocytes), and hold the potential to repair damaged tissue in the central nervous system (CNS) (Bianco \& Robey, 2001; Gage \& Temple, 2013). This makes them invaluable for the development of 3D models for the study of normal and abnormal developmental mechanisms, neurodegenerative disorders, neural repair and high-throughput screening of putative neuroactive drugs (Breier et al., 2010; Gage \& Temple, 2013; Gu et al., 2016). There is also much interest in using hNSC to develop 3D systems for transplantation into the damaged CNS (Somaa et al., 2017; Vishwakarma et al., 2014).

Given the encouraging results from a few studies on mouse neural cells and human astrocytoma (Eagles et al., 2006; Eddaoudi et al., 2010; Jayasinghe \& Townsend-Nicholson, 2006; Mongkoldhumrongkul et al., 2009a), we wished to establish whether hNSCs could be bio-electrosprayed, and specifically assess whether the procedure affected their survival and ability to undergo multi-lineage differentiation. Extensive analysis of hNSC survival/death and differentiation showed that hNSCs withstand the BES procedure very well and could successfully differentiate towards neuronal, astrocyte and oligodendrocyte lineages with no alteration in gene expression following neuronal differentiation. Together, this study demonstrates that hNSCs remain viable over prolonged periods post-treatment and are capable of withstanding the pressure and stresses of being handled as high-density cell suspensions within a needle at a high voltage.

\section{Methods}

\section{Materials}

Unless otherwise indicated, chemicals were purchased from Sigma-Aldrich (UK). Dulbecco's Modified Eagle Medium/Nutrient Mixture F-12 GlutaMAX ${ }^{\mathrm{TM}}$ (DMEM/F12, Thermo Fisher Scientific, 31331028), Neurobasal ${ }^{\circledR}-A$ Medium (Life Technologies, 10888022), foetal bovine serum (FBS, Life Technologies, 10270106), N-2 supplement 100x (Thermo Fisher Scientific, 17502048) and B-27 supplement 50x (Thermo Fisher Scientific, 12587010), human FGF-2 (Peprotech, AF-100-18B), EGF (PeproTech, 100- 15) and PDGF-aa (Peprotech, 10013A-10), and DGF-aa (Peprotech, 100-13A-10), propidium iodide (PI) from Invitrogen and Allophycocyanin (APC) Annexin V from BD Pharmingen 550474 BD).

\section{Human neural stem cell culture}

Human brain embryonic tissue was provided by the Human Developmental Biology Resource (HDBR, http://www.hdbr.org/). All procedures using human tissue were carried out in accordance with the Human Tissue Act 2006 with informed consent (REC reference: $18 / \mathrm{LO} / 0822)$ for study participation under ethical approval (NRES Committee London - Fulham, London, UK). The hNSC lines used in this study had been derived from embryonic brain tissue at Carnegie Stage (Cs)17 and Cs23, and grown on laminin, as previously described (Taylor et al., 2019; U et al., 2014; Vagaska et al., 2016). In brief, cells were seeded at a density of $\sim 11,000$ cells $/ \mathrm{cm}^{2}$ and grown at $37^{\circ} \mathrm{C}$ in a humidified incubator with $5 \% \mathrm{CO}_{2}$ in medium containing: Dulbecco's Modified Eagle Medium/Nutrient Mixture F-12 (DMEM/F12) supplemented with $1 \% \quad(\mathrm{v} / \mathrm{v})$ 
penicillin/streptomycin streptomycin (Life Technologies, 15140122), 1\% (v/v) 100x N2, 2\% (v/v) B27, 20 ng/ml FGF-2, $20 \mathrm{ng} / \mathrm{ml}$ EGF, $50 \mu \mathrm{g} / \mathrm{ml}$, BSA fraction V (85040C), $5 \mu \mathrm{g} / \mathrm{ml}$ heparin (H3149) and $10 \mu \mathrm{g} / \mathrm{ml}$ laminin (L2020).

\section{Differentiation protocols}

Differentiation was induced when hNSCs had reached confluency, approximately 3 days after plating.

Neuronal differentiation. After 10 days in a medium consisting of DMEM containing Glutamax supplemented with $1 \%$ penicillin/ streptomycin, $10 \mu \mathrm{M}$ forskolin (F3917), $5 \mathrm{mM} \mathrm{KCl,} 2 \mathrm{mM}$ valproic acid (P4543), $1 \mu \mathrm{M}$ hydrocortisone and $5 \mu \mathrm{g} / \mathrm{ml}$ insulin (I9278) for 10 days, cells were maintained in with Neurobasal®-A Medium supplemented with 1\% L-glutamine (Thermo Fisher Scientific, 25030-024), $1 \%$ penicillin/streptomycin and $2 \%$ B27 for 18 days (4 weeks total differentiation time). Protocol adapted from Guasti et al. (2012).

Oligodendrocyte differentiation. hNSCs were first incubated in DMEM/F12 containing $1 \%$ penicillin/streptomycin, $1 \% \mathrm{~N} 2$, $10 \mathrm{nM}$ forskolin, $10 \mathrm{ng} / \mathrm{ml} \mathrm{FGF-2} \mathrm{and} 10 \mathrm{ng} / \mathrm{ml} \mathrm{PDGF-aa} \mathrm{for}$ 14 days, and then in DMEM/F12 medium supplemented with $1 \%$ penicillin/streptomycin, $1 \% \mathrm{~N} 2,30 \mathrm{ng} / \mathrm{ml}$ tri-iodothyronine (T6397), $200 \mu \mathrm{M}$ ascorbic acid and $10 \mathrm{ng} / \mathrm{ml}$ PDGF-aa for 7 days. PDGF-aa was then removed and cell incubated for a further 2 weeks to allow maturation ( 5 weeks total differentiation time).

Astrocytic differentiation. This was induced by incubating hNSCs in DMEM/F12 supplemented with $10 \%$ (v/v) FBS and $1 \%$ penicillin/streptomycin for 2 weeks.

\section{BES configuration and cell preparation}

The BES system consisted of a high-voltage power supply (Glassman Europe Ltd., FP-30, Tadley, UK.) with a syringe pump (Harvard Apparatus) holding a needle similar to those used in our previous studies (O'Neill et al., 2019), which is a standard straight cut hypodermic stainless steel needle with $1.5-\mathrm{mm}$ outer diameter and $0.8-0.9 \mathrm{~mm}$ inner diameter. The field strength was $0.2 \mathrm{kv} / \mathrm{mm}(10 \mathrm{kv}$ over $50 \mathrm{~mm})$. The voltage was set at $10 \mathrm{kV}$ and the flow rate at $250 \mathrm{ml} / \mathrm{h}$. Because of the high flow rate, cells were subjected to the voltage for less than a minute. The procedure was carried out inside a class II biosafety cabinet to ensure sterility. hNSC suspensions with a density of $\sim 1.3 \times 10^{6}$ cells per $\mathrm{ml}$ were divided into 1 experimental and 2 control groups, all run in triplicate. The experimental hNSCs were taken to the the bio-electrospray facility, which was located in a different building, and sprayed (BES group). One control group was transported to the BES facility but not sprayed (TC), and the other was left in the tissue culture laboratory (LC). All groups were replated at the same time.

\section{Analysis of cell death and survival}

The live/dead staining was performed 24 hours after BES. Hoechst 33258 and propidium iodide dissolved in phosphate buffered saline (PBS) were added to the culture medium at final concentrations of $2 \mu \mathrm{g} / \mathrm{ml}$ and $5 \mu \mathrm{g} / \mathrm{ml}$, respectively. After a 2-hour incubation, cells were viewed and imaged using an IX71inverted microscope from Olympus equipped with a Lumen 200 metal arc lamp (Prior Scientific) and a monochrome ORCA-R2 digital camera (Hamamatsu Corp.) All images were processed with Fiji software (Java 8 version) (Schindelin et al., 2012).

Cells viability/metabolic activity was assessed 1, 3 and 6 days after BES by the MTT (3-(4, 5-dimethylthiazolyl-2)-2, 5-diphenyltetrazolium bromide) assay. In brief, cells were incubated for 2 hours in medium containing 10\% MTT (stock solution $5 \mathrm{mg} / \mathrm{ml}$ in DMSO), after which the absorbance was measured at $595 \mathrm{~nm}$ with a spectrophotometer (Multiscan FC ThermoScientific).

Flow cytometry analysis was performed immediately after and 3 days after BES. Roughly $1 \times 10^{6}$ hNSCs per sample were resuspended in $500 \mu \mathrm{l}$ of 1:100 APC-Annexin V conjugate:Annexin $\mathrm{V}$ binding buffer (10 $\mathrm{mM}$ HEPES, $150 \mathrm{mM} \mathrm{NaCl}, 5 \mathrm{mM} \mathrm{KCl}$, $5 \mathrm{mM} \mathrm{MgCl}_{2}$ and $1.8 \mathrm{mM} \mathrm{CaCl}_{2}$ adjusted with $\mathrm{NaOH}$ to $\mathrm{pH}$ 7.4). Samples were kept at room temperature (RT) in the dark for 20 minutes before adding propidium iodide (PI) to a final concentration of $5 \mu \mathrm{g} / \mathrm{ml}$. Stained cells were kept on ice until loading on a BD FACSCalibur TM to carry out flow cytometry analysis. Data was analysed using Kaluza 1.3 software. As a positive control, hNSCs were treated with $10 \mu \mathrm{m}$ thapsigargin (T9033) for 24 hours to induce cell death prior to flow cytometry.

\section{Immunocytochemistry}

Cells were fixed with $4 \%$ (w/v) paraformaldehyde (PFA) $\mathrm{pH} 7.4$ for 15 minutes at RT, rinsed in PBS (phosphate buffer saline) and incubated in blocking solution (10\% FBS, 3\% BSA and $0.2 \%$ TritonX-100 in PBS) for 1 hour at RT. Incubation with primary and secondary antibodies at the indicated dilutions (Table 1) was overnight at $4^{\circ} \mathrm{C}$, and for 1 hour at $\mathrm{RT}$, respectively. The nuclear stain Hoechst $33258(2 \mu \mathrm{g} / \mathrm{ml})$ was added to the secondary antibody solution. Cells were mounted with Citifluor (Citifluor Ltd). An IX71inverted microscope (Olympus) with a monochrome ORCA-R2 digital camera (Hamamatsu Corp.) was used to acquire images. All images were processed with Fiji software (Schindelin et al., 2012).

RNA analysis by reverse transcription-PCR (RT-PCR) RNA was extracted from cell pellets using RNeasy Mini Kit (Qiagen) according to the manufacturer's protocol. Complementary DNA (cDNA) was prepared from $500 \mathrm{ng}$ of extracted RNA using MMLV reverse transcriptase (Promega, M1705) following the manufacturers protocol. Reverse transcription reactions were performed using a PTC-100 thermal cycler (MJ Research, Inc.). The sequences of the primers and conditions used are shown in Table 2. PCR reactions were performed in a Veriti Thermal Cycler (Applied Biosciences). To exclude contamination of the reagents, no-template controls (NTC) where water instead of cDNA was included were run in each experiment. A cDNA sample from a human embryonic brain ( 22 weeks post conception) was used as positive controls. Amplified products were separated by gel electrophoresis using $1.5 \%(\mathrm{w} / \mathrm{v})$ agarose gels in tri-acetate EDTA (TAE) buffer and 1X SYBR Safe dye (ThermoFisher Scientific). Semi-quantification of the bands was performed using 
Table 1. Primary and secondary antibodies used for immunofluorescence.

\begin{tabular}{|l|l|l|l|l|l|}
\hline \multicolumn{7}{|c}{ Primary Antibodies } & & & \\
\hline Target & Antibody type (species) & Supplier & $\begin{array}{l}\text { Product } \\
\text { Number }\end{array}$ & Dilution & RRID \\
\hline NeuN & Monoclonal (mouse) & Millipore & MAB377 & $1 / 100$ & AB_2298772 \\
\hline NF200 & Polyclonal (rabbit) & Sigma & N4142 & $1 / 100$ & AB_477272 \\
\hline S100 $\beta$ & Polyclonal (rabbit) & Dako & Z0311 & $1 / 100$ & AB_10013383 \\
\hline DCX & Polyclonal (rabbit) & Invitrogen & $48-1200$ & $1 / 200$ & AB_2533840 \\
\hline MAP2 & Monoclonal (mouse) & Life Technologies & 131500 & $1 / 200$ & AB_2533001 \\
\hline GFAP & Polyclonal (rabbit) & Millipore & AB5804 & $1 / 500$ & AB_2109645 \\
\hline Vimentin & Monoclonal (mouse) & Dako & GA630 & $1 / 500$ & AB_2827759 \\
\hline O4 & Monoclonal (mouse) & R\&D & MAB1326 & $1 / 100$ & AB_357617 \\
\hline A2B5 & Monoclonal (mouse) & R\&D & MAB1416 & $1 / 100$ & AB_357687 \\
\hline Target & Host (fluorophore) & Supplier & $\begin{array}{l}\text { Product } \\
\text { Number }\end{array}$ & Dilution & RRID \\
\hline Mouse IgG & Donkey (Alexa Fluor 488) & Molecular Probes & A-21202 & $1 / 500$ & AB_141607 \\
\hline Rabbit IgG & Donkey (Alexa Fluor 594) & Molecular Probes & A-21207 & $1 / 500$ & AB_141637 \\
\hline Mouse IgM & Goat (Alexa Fluor 488) & Molecular Probes & A-21042 & $1 / 500$ & AB_2535711 \\
\hline
\end{tabular}

Table 2. List of human primers and conditions used for transcript amplification.

\begin{tabular}{|c|c|c|c|}
\hline Gene & Primer Sequences & $\begin{array}{c}\text { Annealing } \\
\text { temperature }\left({ }^{\circ} \mathrm{C}\right)\end{array}$ & $\begin{array}{c}\text { Cycle } \\
\mathrm{N}^{\circ}\end{array}$ \\
\hline GAPDH & $\begin{array}{l}\text { Fw CCTTCATTGACCTCAACTACATGGT } \\
\text { Rv CTAAGCAGTTGGTGGTGCAGGA }\end{array}$ & 56 & 30 \\
\hline MAP2 & $\begin{array}{l}\text { Fw CCACCTGAGATTAAGGATCA } \\
\text { Rv GGCTTACTTTGCTTCTCTGA }\end{array}$ & 59 & 30 \\
\hline OLIG2 & $\begin{array}{l}\text { Fw CAGAAGCGCTGATGGTCATA } \\
\text { Rv TCGGCAGTTTTGGGTTATTC }\end{array}$ & 56 & 32 \\
\hline GFAP & $\begin{array}{l}\text { Fw GAAGCTCCAGGATGAAACCA } \\
\text { Rv ACCTCCTCCTCGTGGATCTT }\end{array}$ & 56 & 30 \\
\hline NEFH (NF-H) & $\begin{array}{l}\text { Fw TAGCCGCTTACAGAAAACTC } \\
\text { Rv AGACTTCTCCACCACTTTGA }\end{array}$ & 56 & 32 \\
\hline $\begin{array}{l}\text { SLC1A3 } \\
\text { (GLAST) }\end{array}$ & $\begin{array}{l}\text { Fw CTCACAGTCACCGCTGTCAT } \\
\text { Rv CCATCTTCCCTGATGCCTTA }\end{array}$ & 56 & 32 \\
\hline ENO2 (NSE) & $\begin{array}{l}\text { Fw CTGATGCTGGAGTTGGATGG } \\
\text { Rv CCATTGATCACGTTGAAGGC }\end{array}$ & 56 & 32 \\
\hline
\end{tabular}

Fiji software (Schindelin et al., 2012) and the housekeeping gene, glyceraldehyde 3-phosphate dehydrogenase (GAPDH), used to normalize expression.

\section{Statistical analysis}

Each experiment was performed in biological triplicates unless stated otherwise. Statistical analysis was carried out with two-way ANOVA followed by Tukey's multiple comparison test.
Results are expressed as mean \pm standard error of the mean. Differences were considered to be significant if $\mathrm{p} \leq 0.05$.

\section{Results}

Assessment of hNSC viability after BES

We first investigated whether hNSC viability is affected immediately after and at different times after bioelectrospraying (BES). Three groups were compared in all experiments: 
bio-electrosprayed hNSCs (BES) and two control groups, the BES control hNSCs (cells transported to the BES laboratory, but not sprayed; TC) and the tissue culture laboratory control hNSCs (cells not transported to the BES laboratory; LC).

At 24 hours after spraying, cells were double stained with Hoechst dye and PI to detect dead cells. No apparent difference in cell death between BES and control groups was observed by cell imaging (Figure 1A). To further assess the effect of BES on cell viability, hNSCs were labelled with PI and annexin V, a marker of apoptosis, immediately after spraying (Figure 1B) and 3 days later (Figure 1C). Cells were analysed by flow cytometry to detect early apoptotic (low PI and high APC-Annexin V), and late apoptotic/necrotic cells (high PI) as shown in Figure 1B, C. As summarized in Figure 1D, over 94\% of cells were viable in all groups immediately after spraying (Day 0), and over $95 \%$ were viable at 3 days, with low levels of early apoptosis detected at both time points ( $1 \%$ and $0.5 \%$, respectively). To establish whether BES affected cell behaviour over time, their metabolic activity, that reflects number of cells in the culture, was assessed by the MTT assay on day 1, 3 and 6 after BES. Metabolic activity increased over six days in all samples, although it was lower in the BES group than in the laboratory control at 1 and 3 days; however, by 6 days, no difference was observed among control and BES groups (Figure 1E). Together, these results suggest that BES does not negatively affect hNSCs viability over time.

Assessment of hNSCs differentiation potential after BES

To establish whether BES affected hNSCs differentiation capacity, two hNSCs lines were differentiated along the neuronal and glial lineages (astrocytes and oligodendrocytes). After 4 weeks of neuronal differentiation, processes that had started to grow at 10 days (see Extended data) had extended further in all groups, as shown by phase contrast images (Figure 2 and Extended data, Supplementary Figure S2) (Ferretti \& Helenes González, 2020b). Immunofluorescence labelling for neuronal markers revealed comparable expression of the mature neuronal markers microtubule-associated protein 2 (MAP2), neurofilament 200 (NF200) and neuronal nuclear protein (NeuN) (Figure 2 and Extended data, Supplementary Figure S1 and S2) (Ferretti \& Helenes González, 2020b) in the control and BES groups. In contrast, no significant expression of doublecortin (DCX), a marker of newly born and migrating neurons was detected in any group (Extended data, Supplementary Figure S1) (Ferretti \& Helenes González, 2020b). These indicated that the BES process did not compromise hNSC neuronal differentiation.

Upon induction of astrocyte differentiation, hNSC morphology rapidly changed in both control and BES groups, with cells becoming more spread and flatter than in undifferentiated controls, consistent with astrocytic differentiation (Figure 3 and Extended data, Supplementary Figure S3) (Ferretti \& Helenes Gonzalez, 2020b). This was further supported by expression of vimentin and glial fibrillary acidic protein (GFAP). Together, comparable morphological appearance and glial markers expression in all groups indicates that BES does not interfere with astrocytic differentiation of hNSCs.
Finally, the effect of BES on oligodendrocyte differentiation was tested. At 5 weeks of differentiation after BES, both control and BES cultures had acquired a branched morphology with long processes (Figure 4 and Extended data, Supplementary Figure S4) (Ferretti \& Helenes González, 2020b). Labelling of oligodendrocyte progenitor markers revealed a few cells positive for the oligodendrocyte marker, O4 (Figure 4 and Extended data, Supplementary Figure S4) (Ferretti \& Helenes González, 2020b), and several positive for A2B5, that is expressed in oligodendrocyte progenitor cells (Figure 4). There was no visible difference in the expression of these markers between BES cells and their controls, indicating that the BES process does not alter the oligodendrocyte differentiation.

\section{Effect of BES on gene expression in neuronally differentiated hNSCs}

The effect of BES on neuronal differentiation was further investigated at the gene expression level in hNSCs after 4 weeks of neuronal differentiation. As mixed cultures are normally obtained following neuronal induction, rather than pure neuronal populations, both neuronal and glial markers were assessed to establish whether BES changed the balance of differentiation among these cell types. Transcripts for the neuronal markers, NF200, neuron-specific enolase (NSE) and MAP2, as well as the glial markers glutamate aspartate transporter (GLAST), Olig2 and GFAP were detected in all groups by RT-PCR (Figure 5A-C and Extended data, Supplementary Figure S5A-C) (Ferretti \& Helenes González, 2020b). To obtain more quantitative information, gene expression was further investigated by semi-quantitative RT-PCR analysis in two hNSC lines (Figure 5D and Extended data, Supplementary Figure S5D) (Ferretti \& Helenes González, 2020b). Relative expression of genes was normalised to GAPDH. No significant differences in glial marker expression between the control and BES groups was observed in either line. Also, neuronal markers were expressed at comparable levels, with the exception of NF200, which was expressed at slightly higher levels in the BES group in one of the cell lines (Extended data, Supplementary Figure S5D) (Ferretti \& Helenes González, 2020b). Overall, the expression of all but one marker were unchanged, suggesting no significant effects resulted from BES.

\section{Discussion}

Only a few studies on the effect of BES on human cells have been carried out; these focussed on human mesenchymal stem cells (MSCs), either primary or hTERT immortalized, and tumour cells (Braghirolli et al., 2013; Eddaoudi et al., 2010; Mongkoldhumrongkul et al., 2009a; Ye et al., 2015). In this study, to our knowledge we show for the first time that hNSCs can withstand the BES procedure without any negative effect on their self-renewal capacity and importantly on their neuronal and glial differentiation potential. The high voltage of $10 \mathrm{kV}$ used here, the pressure applied by the syringe pump, the flow rate, the high-density solution in a small-bore needle $(0.8-0.9 \mathrm{~mm})$ and the handling of the cells in a separate laboratory had limited impact on hNSCs. It is well established that high voltages can be detrimental to cells, for example when cells are electroporated (Traitcheva \& Berg, 2010). However, the fact that BES operates 
A
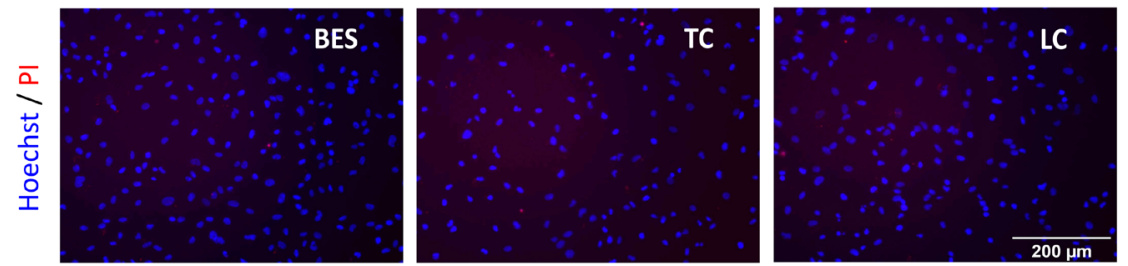

B
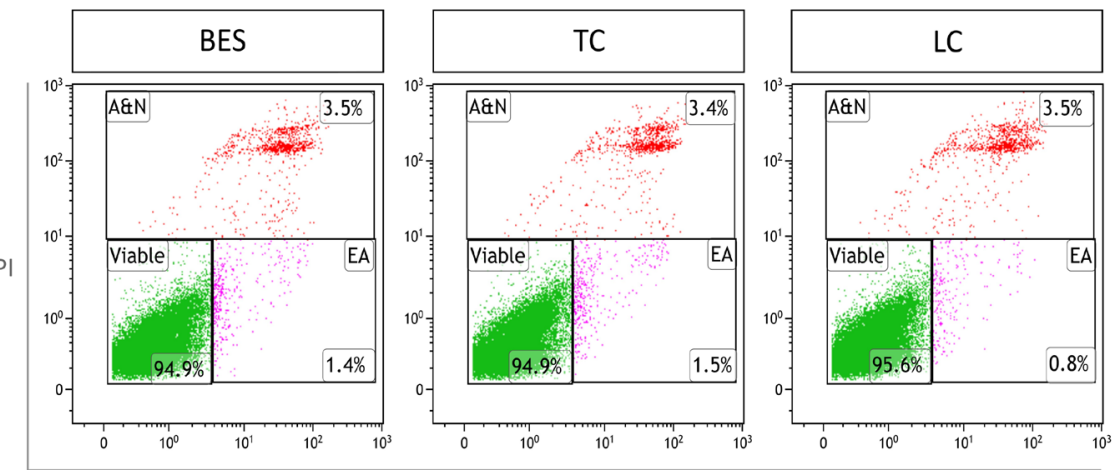

Annexin V

C
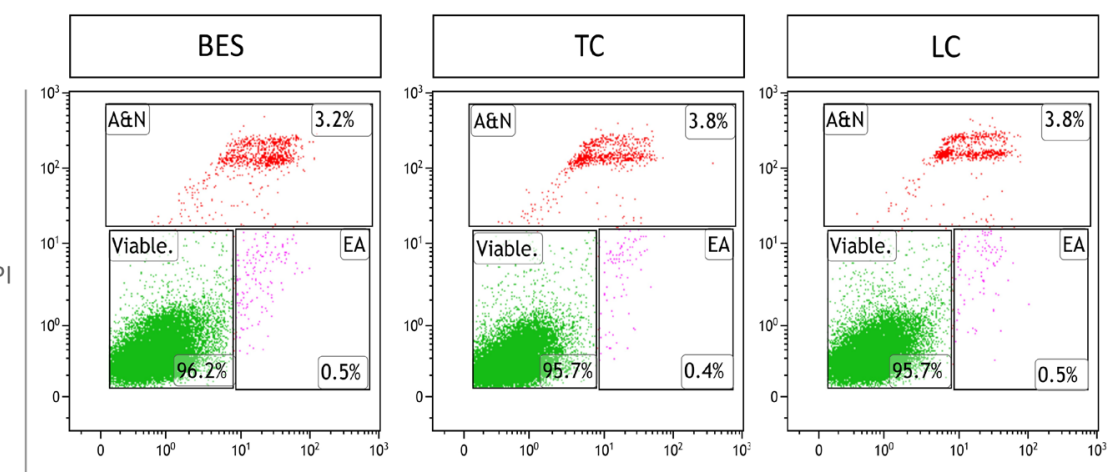

Annexin V

D

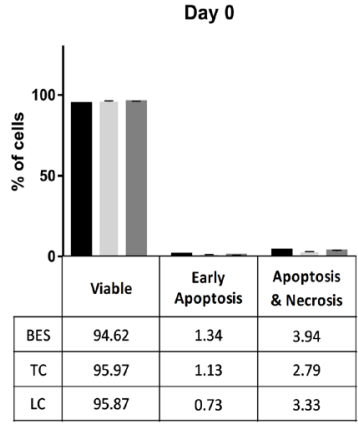

Day 3

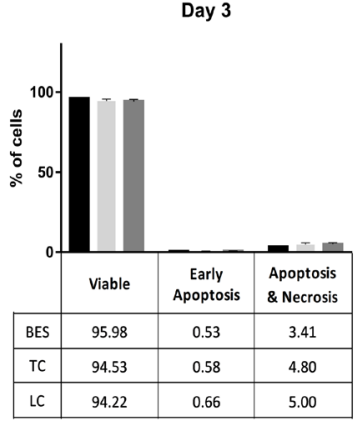

BES

TC LC
E

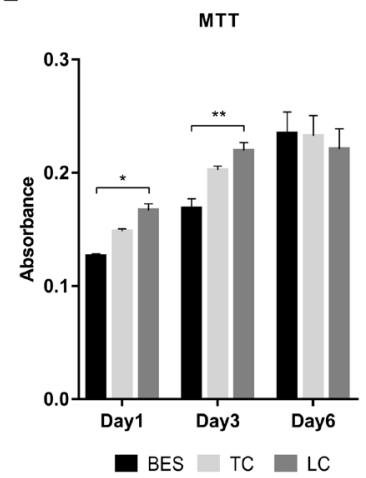

Figure 1. Viability of human neural stem cells (hNSCs) after bio-electrospray. A) Staining with propidium iodide (PI, red) and Hoechst 33258 (blue) in live hNSCs (Cs 17, passage 22) 24 hours after spraying (BES) and in non-sprayed controls (TC: taken to the BES laboratory but non-sprayed; LC: not moved from the tissue culture laboratory). All pictures are at the same magnification. B-C) Analysis of Annexin $\mathrm{V}$ - and PI- positive cells by flow cytometry immediately after spraying (B) and 3 days after spraying (C). Representative scatter plots showing early apoptotic (EA), and apoptotic plus necrotic cell population (A\&N) measured as percentages of total gated cells. D) Cell populations represented as percentages of total gated cells. No significant difference in the percentage of viable cells is observed between BES and controls (biological triplicates presented as mean \pm SEM) as assessed by two way ANOVA. E) hNSC metabolic activity assessed by the MTT assay 1,3 and 6 days after BES. Data represent mean absorbance \pm SEM, $n=6 ;{ }^{*} \leq p 0.05,{ }^{* *} p \leq 0.01$ as assessed by two way ANOVA and Tukey's multiple comparisons test. 

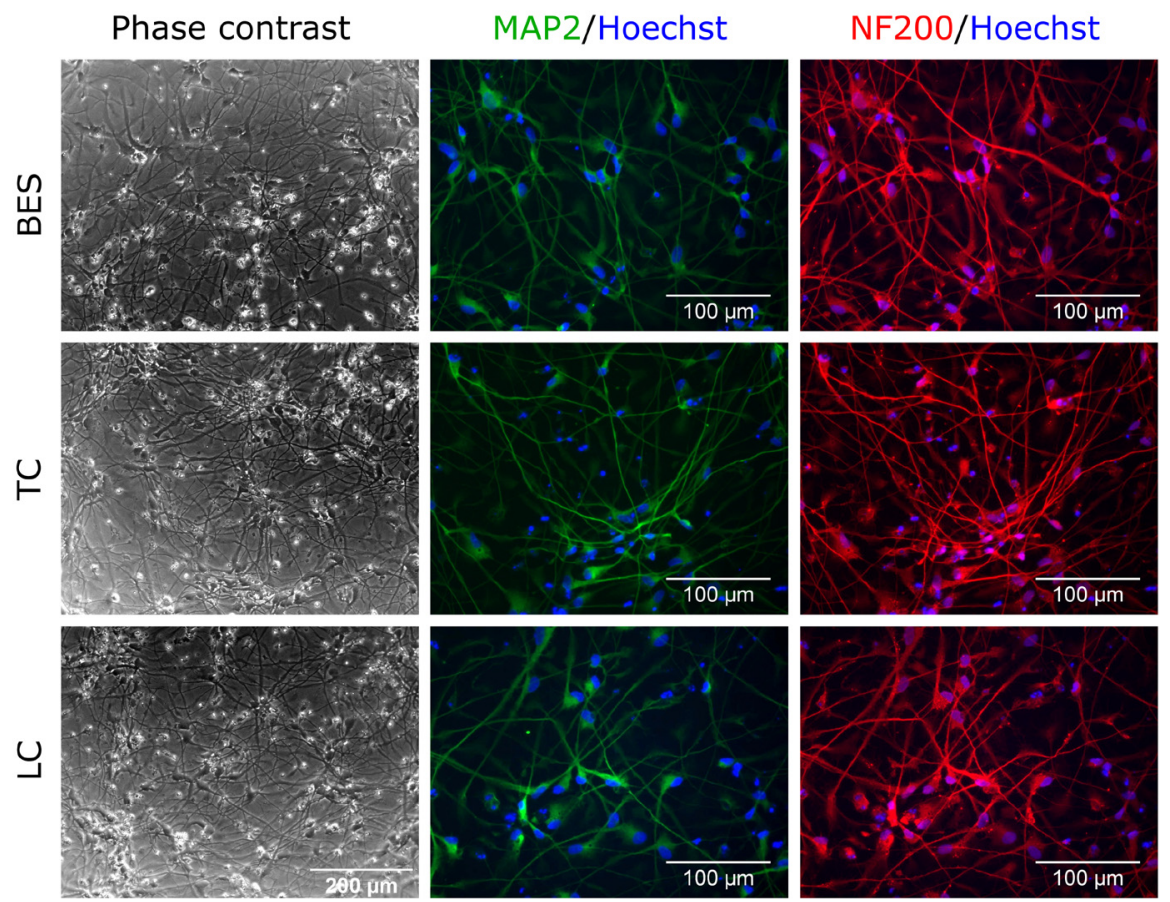

Figure 2. Neuronal differentiation of hNSCs after bio-electrospray assessed by phase contrast imaging and double-labelling for neuronal markers. Sprayed (BES) and control (TC: taken to the BES laboratory but non-sprayed; LC: not moved from the tissue culture laboratory) hNSCs (Cs 17, passage 22) differentiated for 4 weeks. Note typical neuronal morphology and neurite extension and expression of the neuronal markers, MAP2, microtubule-associated protein 2 (green), and NF200, neurofilament 200 (red). Nuclei are counterstained with Hoechst 33258 (blue). All phase contrast images are at the same magnification.

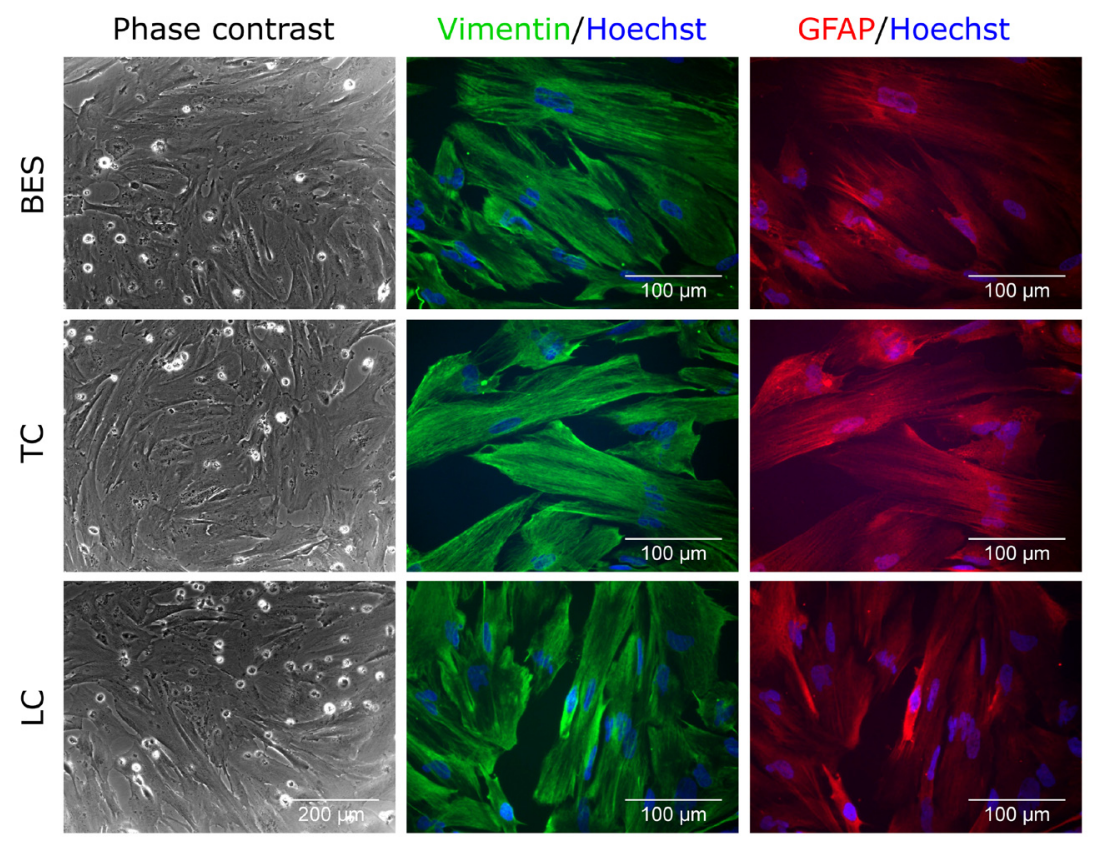

Figure 3. Astrocyte differentiation of hNSCs after bio-electrospray assessed by phase contrast imaging and double-labelling for astrocyte markers. Sprayed (BES) and control (TC: taken to the BES laboratory but non-sprayed; LC: not moved from the tissue culture laboratory) hNSCs (Cs 17, passage 22) differentiated for 2 weeks. Note the flatten morphology typical of astrocytes morphology and expression of astrocyte markers, Vimentin (green) and GFAP (glial fibrillary acidic protein; red). Nuclei are counterstained with Hoechst 33258 (blue). All phase contrast images are at the same magnification. 

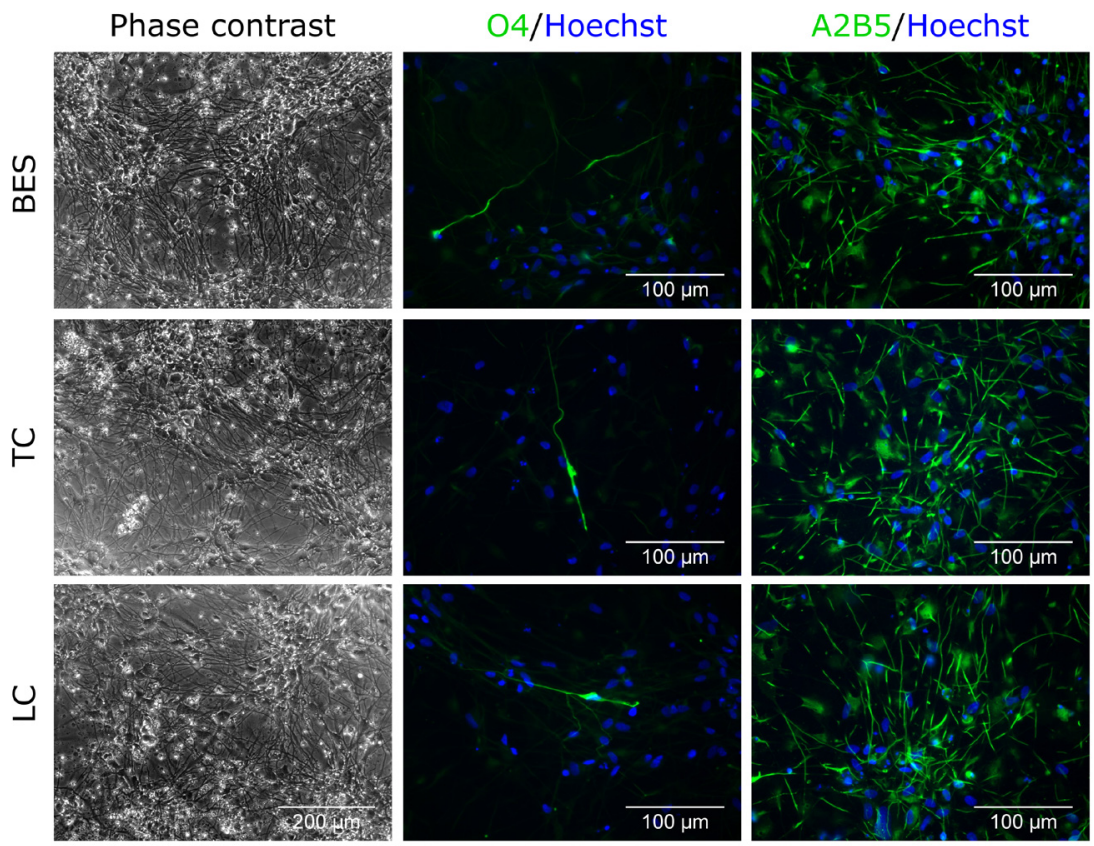

Figure 4. Oligodendrocyte differentiation of hNSC assessed after bio-electrospray by phase contrast imaging and immunostaining. Sprayed (BES) and control (TC: taken to the BES laboratory but non-sprayed; LC: not moved from the tissue culture laboratory) hNSCs (Cs 17, passage 22) differentiated for 5 weeks. Note the presence of cells with different morphologies with a few expressing the oligodendrocyte marker, O4, and a larger proportion the glial precursor marker, A2B5. Nuclei are counterstained with Hoechst 33258 (blue). All phase contrast images are the same magnification.

at high voltage but low current, in the nano-ampere range (Pakes et al., 2011; Poncelet et al., 2012), could help explain why cells do not show adverse effects when subjected to high voltages. Recently, a study assessing the effect of bioprinting on Schwann cells and myoblasts has suggested that this technique affects their viability and proliferative activity (Ning et al., 2018). Therefore, at least for some cell types, BES could provide a valuable alternative to bioprinting.

\section{hNSCs viability is not affected by BES}

Our findings on the safety of BES on hNSCs are consistent with findings in a number of cell types and organisms previously investigated, including mesenchymal cells (Hong et al., 2010; Irvine et al., 2007; Jayasinghe et al., 2011; Ye et al., 2015), immortalised mouse neural cells and human astrocytoma cells (Eagles et al., 2006; Eddaoudi et al., 2010; Jayasinghe \& Townsend-Nicholson, 2006), and nematodes (Mongkoldhumrongkul et al., 2010). In all these studies, a survival of up to $90 \%$ after BES was observed. Notably, the hNSCs displayed an even higher survival rate (>94\%), suggesting that these human stem cells are more robust than most of the cells previously studied.

Another difference between previous studies and ours is the length of time we monitored the cells for. Here, not only we measured metabolic activity up to 6 days, but also monitored the cells over weeks in the differentiation experiments, where undifferentiated controls were run in parallel. The use of two controls also showed that an initial small decrease in metabolic activity on BES samples was partly due to the transfer of the samples to the BES laboratory, and that full recovery had occurred by day 6. Viability of rabbit bone marrow-derived MSCs after BES was lower than that of hNSCs, with a metabolic/proliferation rate significantly lower than in controls even at a lower bio-electrospraying voltage than that used in our study (Sahoo et al., 2010). Together, the combination of cell death and survival assays and long-term monitoring used here provides clear evidence that BES does not affect hNSCs viability either immediately or over time.

hNSCs differentiation potential is maintained after BES

Our tri-lineage differentiation study has clearly shown no changes in hNSC differentiation potential after BES. As from previous reports, hNSC induction of neuronal differentiation resulted in a heterogeneous population of cells, and this was comparable across groups as shown by mRNA expression (Glaser et al., 2007; $\mathrm{Gu}$ et al., 2016; Sun et al., 2008). Astrocytic differentiation resulted in a more homogeneous population and all cells expressed vimentin and GFAP, though at different extents. The low number of cells positive for the oligodendrocyte marker $\mathrm{O} 4$ upon induction of oligodendrocyte differentiation is comparable in control and BES groups, and consistent with the long time required for human oligodendrocyte maturation. Indeed, a marker of less mature cells, A2B5, was expressed in a much higher proportion of cells.

This again supports the view that hNSCs are very resistant to external stimuli. This may be a property of human stem cells or of neural stem cells, or both, and extensive investigation will be required to compare stem cell types across species to clarify 
A

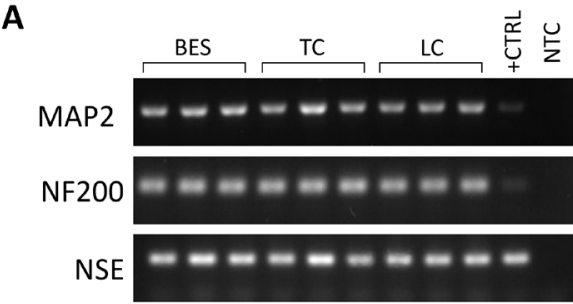

B

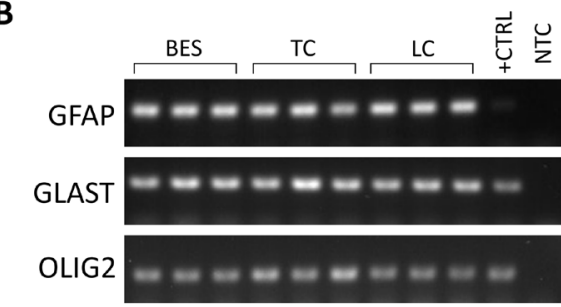

C

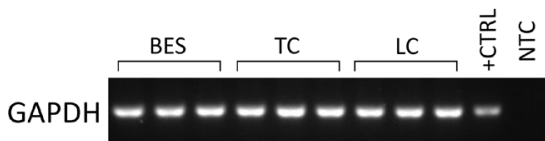

D

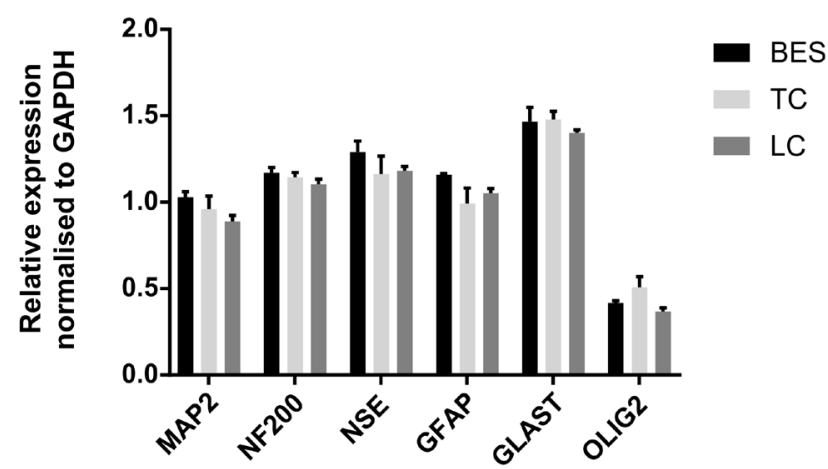

Figure 5. Expression of neural markers in hNSCs neuronally differentiated for $\mathbf{4}$ weeks after bio-electrospray assessed by RTPCR. A-C. Expression of neuronal markers (A), glial markers (B), and a reference house-keeping gene, GAPDH, (C) in biological triplicates of sprayed (BES) and control (TC: taken to the BES laboratory but non-sprayed; LC: not moved from the tissue culture laboratory) hNSCs (Cs 17, passage 25). MAP2: microtubule-associated protein 2; NF200: neurofilament 200; NSE: neuron-specific enolase; GFAP: glial fibrillary acidic protein; GLAST: glutamate aspartate transporter; OLIG2: oligodendrocyte transcription factor 2; GAPDH: glyceraldehyde 3-phosphate dehydrogenase. +CTRL: human embryonic brain cDNA used as positive control; NTC: no template control using water instead of CDNA. D) Relative expression of neuronal and glial markers assessed by densitometry. Data are means \pm SEM of band intensity normalised to GAPDH. No significant difference in gene expression is observed (two way ANOVA).

this issue. Rabbit bone marrow-derived MSCs have been shown to maintain differentiation potential along three mesenchymal lineages after BES at a lower voltage than the one used here (Sahoo et al., 2010). By contrast, human MSCs derived from human deciduous tooth pulp appear to better withstand BES even at higher voltage $(15 \mathrm{kV})$, as well as maintain tri-lineage differentiation potential (Braghirolli et al., 2013; Braghirolli et al., 2015). Also human adipose-derived MSCs (ADSCs) survived and differentiated efficiently after BES (Ye et al., 2015).

\section{Conclusion}

Analysis of cell viability, tri-lineage differentiation capacity and gene expression demonstrated that the BES process does not adversely affect hNSCs either in the short or long term. Notably, it highlighted the robustness of these human stem cells. In conclusion, this study shows that BES is a suitable tool for the direct handling of hNSCs. Therefore, it may provide a suitable technology for deposition of hNSCs to specific locations in damaged nervous system in vivo or within suitable scaffolds for neural tissue engineering. Furthermore, this approach could be developed to generate well-controlled human neural 3D models for studying neural development or disease and responses to putative novel therapeutic interventions.

\section{Data availability}

Underlying data

Harvard Dataverse: Bio-electrosprayed human neural stem cells are viable and maintain their differentiation potential- Underlying data of main figures. https://doi.org/10.7910/DVN/CAASEG (Ferretti \& Helenes González, 2020a).

This project contains the raw uncropped images used to produce each figure, in addition to flow cytometry, cell viability and RT-PCR output data.

Harvard Dataverse: Bio-electrosprayed human neural stem cells are viable and maintain their differentiation potential- Underlying data of supplementary figures. https://doi.org/10.7910/DVN/ CLGEWR (Ferretti, 2020).

This project contains the raw uncropped images used to produce each of the supplementary figures (see Extended data), in addition to RT-PCR output data for Supplementary Figure S5D.

\section{Extended data}

Harvard Dataverse: Bio-electrosprayed human neural stem cells are viable and maintain their differentiation potential- Extended data. https://doi.org/10.7910/DVN/M8ZFNR (Ferretti \& Helenes González, 2020b).

This project contains the file 'Supplementary figures.pdf', which contains the following extended data:

- Figure S1 Expression of neuronal markers in hNSCs after 4 weeks of differentiation. (A-B) Neuronal nuclear protein $(\mathrm{NeuN})$ and doublecortin $(\mathrm{DCX})$ in sprayed (BES) and control (TC: taken to the BES laboratory but non-sprayed; LC: not moved from the tissue culture laboratory) in two hNSC lines, Cs 17, passage 22 (A) 
and Cs23, passage 20 (B). Nuclei are counterstained with Hoechst 33258 (blue).

- $\quad$ Figure S2. Neuronal differentiation of hNSCs after bio-electrospray assessed by phase contrast imaging and double-labelling for neuronal markers. Sprayed (BES) and control (TC: taken to the BES laboratory but non-sprayed; LC: not moved from the tissue culture laboratory) hNSCs (Cs 23, passage 20) differentiated for 4 weeks. Note typical neuronal morphology and neurite extension and expression of the neuronal markers, MAP2, microtubule-associated protein 2 (green), and NF200, neurofilament 200 (red). Nuclei are counterstained with Hoechst 33258 (blue). All phase contrast images are at the same magnification.

- Figure S3. Astrocyte differentiation of hNSCs after bio-electrospray assessed by phase contrast imaging and double-labelling for astrocyte markers. Sprayed (BES) and control (TC: taken to the BES laboratory but non-sprayed; LC: not moved from the tissue culture laboratory) hNSCs (Cs 23, passage 20) differentiated for 2 weeks. Note the flatten morphology typical of astrocytes morphology and expression of astrocyte markers, Vimentin (green) and GFAP (glial fibrillary acidic protein; red). Nuclei are counterstained with Hoechst 33258 (blue). All phase contrast images are at the same magnification.

- Figure S4. Oligodendrocyte differentiation of hNSC assessed after bio-electrospray by phase contrast imaging and immunostaining. Sprayed (BES) and control (TC: taken to the BES laboratory but non-sprayed; LC: not moved from the tissue culture laboratory) hNSCs (Cs 23, passage 20) differentiated for 5 weeks. Note the presence of cells with different morphologies with a few expressing the oligodendrocyte marker, O4, and a larger proportion the glial precursor marker, A2B5. Nuclei are counterstained with Hoechst 33258 (blue). All phase contrast images are the same magnification.
- Figure S5. Expression of neural markers in hNSCs neuronally differentiated for 4 weeks after bioelectrospray assessed by RT-PCR. (A-C) Expression of neuronal markers (A), glial markers (B), and a reference house-keeping gene $(\mathrm{C})$ in biological triplicates of sprayed (BES) and control (TC: taken to the BES laboratory but non-sprayed; LC: not moved from the tissue culture laboratory) hNSCs (Cs 23, passage 22). MAP2: microtubuleassociated protein 2; NF200: neurofilament 200; NSE: neuron-specific enolase; GFAP: glial fibrillary acidic protein; GLAST: glutamate aspartate transporter; OLIG2: oligodendrocyte transcription factor 2; GAPDH: glyceraldehyde 3-phosphate dehydrogenase. +CTRL: human embryonic brain cDNA used as positive control (22 weeks post conception); NTC: no template control using water instead of cDNA. (D) Relative expression of neuronal and glial markers assessed by densitometry. Data are means \pm SEM of band intensity normalised to GAPDH. Increased NF200 expression (* $p$ 0.05) is observed in the BES group (two way ANOVA with Tukey's multiple comparisons test).

Data are available under the terms of the Creative Commons Zero "No rights reserved" data waiver (CC0 1.0 Public domain dedication).

\section{Author contributions}

CHG designed and performed experiments, analysed data, obtained funding and wrote the manuscript; SNJ advised and provided training on bio-electrospray and reviewed the manuscript; PF planned research, obtained funding, and wrote the manuscript.

\section{Acknowledgements}

We wish to thank Dr Dale Moulding at the ICH Microscopy Facility for his advice on image acquisition and Dr Ayad Eddaoudi for help with flow cytometry data acquisition.
Bianco P, Robey PG: Stem cells in tissue engineering. Nature. 2001; 414(6859): $118-21$.

PubMed Abstract | Publisher Full Text

Boda SK, Li X, Xie J: Electrospraying an enabling technology for pharmaceutical and biomedical applications: A review. J Aerosol Sci. 2018; 125 : 164-181.

PubMed Abstract | Publisher Full Text | Free Full Text

Braghirolli DI, Zamboni F, Acasigua GAX, et al.: Association of electrospinning with electrospraying: a strategy to produce 3D scaffolds with incorporated stem cells for use in tissue engineering. Int J Nanomedicine. 2015; 10: 5159-69. PubMed Abstract | Publisher Full Text | Free Full Text

Braghirolli DI, Zamboni F, Chagastelles PC, et al:: Bio-electrospraying of human mesenchymal stem cells: an alternative for tissue engineering. Biomicrofluidics. 2013; 7(4): 44130.

PubMed Abstract | Publisher Full Text | Free Full Text

Breier JM, Gassmann K, Kayser R, et al:: Neural progenitor cells as models for high-throughput screens of developmental neurotoxicity: state of the science. Neurotoxicol Teratol. 2010; 32(1): 4-15.

PubMed Abstract | Publisher Full Text

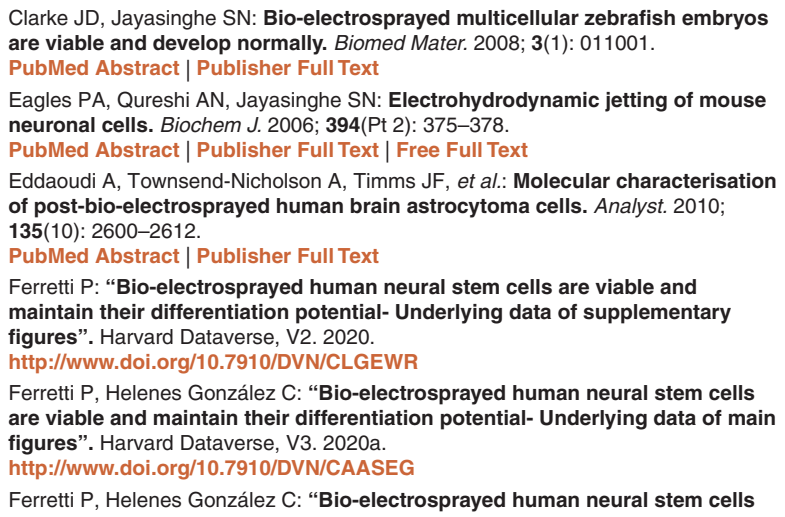

Clarke JD, Jayasinghe SN: Bio-electrosprayed multicellular zebrafish embryos are viable and develop normally. Biomed Mater. 2008; 3(1): 011001. PubMed Abstract | Publisher Full Text

Eagles PA, Qureshi AN, Jayasinghe SN: Electrohydrodynamic jetting of mouse neuronal cells. Biochem J. 2006; 394(Pt 2): 375-378.

PubMed Abstract | Publisher Full Text | Free Full Text

Eddaoudi A, Townsend-Nicholson A, Timms JF, et al:: Molecular characterisation of post-bio-electrosprayed human brain astrocytoma cells. Analyst. 2010; 135(10): 2600-2612.

PubMed Abstract | Publisher Full Text

Ferretti P: "Bio-electrosprayed human neural stem cells are viable and maintain their differentiation potential- Underlying data of supplementary figures". Harvard Dataverse, V2. 2020. http://www.doi.org/10.7910/DVN/CLGEWR

Ferretti P, Helenes González C: "Bio-electrosprayed human neural stem cells are viable and maintain their differentiation potential- Underlying data of main figures". Harvard Dataverse, V3. 2020a.

http://www.doi.org/10.7910/DVN/CAASEG

Ferretti P, Helenes González C: "Bio-electrosprayed human neural stem cells 
are viable and maintain their differentiation potential- Extended data". Harvard Dataverse, V1. 2020b.

http://www.doi.org/10.7910/DVN/M8ZFNR

Gage FH, Temple S: Neural stem cells: generating and regenerating the brain. Neuron. 2013; 80(3): 588-601.

PubMed Abstract | Publisher Full Text

Geach TJ, Mongkoldhumrongkul N, Zimmerman LB, et al:: Bio-electrospraying living Xenopus tropicalis embryos: investigating the structural, functional and biological integrity of a model organism. Analyst. 2009; 134(4): 743-747. PubMed Abstract | Publisher Full Text

Glaser T, Pollard SM, Smith A, et al.: Tripotential differentiation of adherently expandable neural stem (NS) cells. PLOS One. 2007; 2(3): e298.

PubMed Abstract | Publisher Full Text | Free Full Text

Greig D, Jayasinghe SN: Genomic, genetic and physiological effects of bioelectrospraying on live cells of the model yeast Saccharomyces cerevisiae. Biomed Mater. 2008; 3(3): 034125.

PubMed Abstract | Publisher Full Text

Guasti L, Prasongchean W, Kleftouris G, et al:: High plasticity of pediatric adipose tissue-derived stem cells: too much for selective skeletogenic differentiation? Stem Cells Transl Med. 2012; 1(5): 384-395.

PubMed Abstract | Publisher Full Text | Free Full Text

Gu Q, Tomaskovic-Crook E, Lozano R, et al:: Functional 3D Neural Mini-Tissues from Printed Gel-Based Bioink and Human Neural Stem Cells. Adv Healthc Mater. 2016; 5(12): 1429-1438.

PubMed Abstract | Publisher Full Text

Hall RP, Ogilvie CM, Aarons E, et al:: Genetic, genomic and physiological state studies on single-needle bio-electrosprayed human cells. Analyst. 2008; 133(10): 1347-1351.

PubMed Abstract | Publisher Full Text

Hong J, deMello AJ, Jayasinghe SN: Bio-electrospraying and droplet-based microfluidics: control of cell numbers within living residues. Biomed Mater. 2010; 5(2): 21001.

PubMed Abstract | Publisher Full Text

Irvine S, Arumuganathar S, McEwan JR, et al.: Coaxial Aerodynamically Assisted Bio-jets: A Versatile Paradigm for Directly Engineering Living Primary

Organisms. Eng Life Sci. 2007; 7(6): 599-610.

Publisher Full Text

Jayasinghe SN: Bio-electrosprays: from bio-analytics to a generic tool for the health sciences. Analyst. 2011; 136(5): 878-890.

PubMed Abstract | Publisher Full Text

Jayasinghe SN, Eagles PA, Qureshi AN: Electric field driven jetting: an emerging approach for processing living cells. Biotechnol J. 2006; 1(1): 86-94.

PubMed Abstract | Publisher Full Text

Jayasinghe SN, Townsend-Nicholson A: Stable electric-field driven cone-jetting of concentrated biosuspensions. Lab Chip. 2006; 6(8): 1086-1090.

PubMed Abstract | Publisher Full Text

Jayasinghe SN, Warnes G, Scotton CJ: Bio-electrosprayed living composite matrix implanted into mouse models. Macromol Biosci. 2011; 11(10): 1364-1369.

PubMed Abstract | Publisher Full Text

Joly $\mathrm{P}$, Jennings $\mathrm{BH}$, Jayasinghe $\mathrm{SN}$ : Development and fertility studies on post-bio-electrosprayed Drosophila melanogaster embryos. Biomicrofluidics. 2009; 3(4): 44107.

PubMed Abstract | Publisher Full Text | Free Full Text

Mongkoldhumrongkul N, Flanagan JM, Jayasinghe SN: Direct jetting approaches for handling stem cells. Biomed Mater. 2009a; 4(1): 015018.

PubMed Abstract | Publisher Full Text

Mongkoldhumrongkul N, Swain SC, Jayasinghe SN, et al.: Bio-electrospraying the nematode Caenorhabditis elegans: studying whole-genome transcriptiona responses and key life cycle parameters. J R Soc Interface. 2010; 7(45):
595-601

PubMed Abstract | Publisher Full Text | Free Full Tex

Ning L, Betancourt N, Schreyer D, et al.: Characterization of Cell Damage and Proliferative Ability during and after Bioprinting. ACS Biomater Sci Eng. 2018; 4(11): 3906-3918.

Publisher Full Text

O'Neill HC, Maalouf WE, Harper JC, et al.: Bio-electrosprayed human sperm remain viable. Materials Today. 2019; 31: 21-30.

Publisher Full Text

Pakes NK, Jayasinghe SN, Williams RS: Bio-electrospraying and aerodynamically assisted bio-jetting the model eukaryotic Dictyostelium discoideum: assessing stress and developmental competency post treatment. $J$ R Soc Interface. 2011; 8(61): 1185-1191.

PubMed Abstract | Publisher Full Text | Free Full Text

Poncelet D, de Vos $\mathrm{P}$, Suter N, et al.: Bio-electrospraying and cell electrospinning: progress and opportunities for basic biology and clinical sciences. Adv Healthc Mater. 2012; 1(1): 27-34.

PubMed Abstract | Publisher Full Text

Sahoo S, Lee WC, Goh JC, et al.: Bio-electrospraying: A potentially safe technique for delivering progenitor cells. Biotechnol Bioeng. 2010; 106(4): 690-698.

PubMed Abstract | Publisher Full Text

Schindelin J, Arganda-Carreras I, Frise E, et al.: Fiji: an open-source platform for biological-image analysis. Nat Methods. 2012; 9(7): 676-682.

PubMed Abstract | Publisher Full Text | Free Full Text

Somaa FA, Wang TY, Niclis JC, et al:: Peptide-Based Scaffolds Support

Human Cortical Progenitor Graft Integration to Reduce Atrophy and Promote Functional Repair in a Model of Stroke. Cell Rep. 2017; 20(8): 1964-1977. PubMed Abstract | Publisher Full Text

Sun Y, Pollard S, Conti L, et al.: Long-term tripotent differentiation capacity of human neural stem (NS) cells in adherent culture. Mol Cell Neurosci. 2008; 38(2): 245-258.

PubMed Abstract | Publisher Full Tex

Taylor AC, Helenes González C, Ferretti P, et al:: Spontaneous differentiation of human neural stem cells on nanodiamond. Adv Biosyst. 2019; 3(4): 1800299.

Publisher Full Text

Tezera LB, Bielecka MK, Chancellor A, et al: Dissection of the host-pathogen interaction in human tuberculosis using a bioengineered 3-dimensional model. eLife. 2017: 6: pii: e21283.

PubMled Abstract | Publisher Full Text | Free Full Text

Traitcheva N, Berg H: Electroporation and alternating current cause membrane permeation of photodynamic cytotoxins yielding necrosis and apoptosis of cancer cells. Bioelectrochemistry. 2010; 79(2): 257-260.

PubMed Abstract | Publisher Full Text

U KP, Subramanian V, Nicholas AP, et al: Modulation of calcium-induced cell death in human neural stem cells by the novel peptidylarginine deiminase-AIF pathway. BBA Mol Cell Res. 2014; 1843(6): 1162-1171.

PubMed Abstract | Publisher Full Text | Free Full Text

Vagaska B, New SEP, Alvarez-González C, et al: MHC-class-II are expressed in a subpopulation of human neural stem cells in vitro in an IFN $\gamma$-independent fashion and during development. Sci Rep. 2016; 6: 24251.

PubMed Abstract | Publisher Full Text | Free Full Text

Vishwakarma SK, Bardia A, Tiwari SK, et al: Current concept in neural regeneration research: NSCs isolation, characterization and transplantation in various neurodegenerative diseases and stroke: A review. J Adv Res. 2014 5(3): 277-294

PubMed Abstract | Publisher Full Text | Free Full Text

Ye C, He Z, Lin Y, et al.: Bio-electrospraying is a safe technology for delivering human adipose-derived stem cells. Biotechnol Lett. 2015; 37(2): 449-456. PubMed Abstract | Publisher Full Text 


\section{Open Peer Review}

\section{Current Peer Review Status:}

\section{Version 2}

Reviewer Report 18 August 2020

https://doi.org/10.5256/f1000research.27411.r68464

(C) 2020 Xie J. This is an open access peer review report distributed under the terms of the Creative Commons Attribution License, which permits unrestricted use, distribution, and reproduction in any medium, provided the original work is properly cited.

\section{Jingwei Xie}

Department of Surgery-Transplant and Mary and Dick Holland Regenerative Medicine Program, College of Medicine, University of Nebraska Medical Center, Omaha, NE, USA

No further comments.

Competing Interests: No competing interests were disclosed.

Reviewer Expertise: Electrospray, Biomaterials, Tissue Regeneration

I confirm that I have read this submission and believe that I have an appropriate level of expertise to confirm that it is of an acceptable scientific standard.

Reviewer Report 03 August 2020

\section{https://doi.org/10.5256/f1000research.27411.r68466}

(C) 2020 Davies J. This is an open access peer review report distributed under the terms of the Creative Commons Attribution License, which permits unrestricted use, distribution, and reproduction in any medium, provided the original work is properly cited.

\section{Jamie A. Davies}

Deanery of Biomedical Sciences, University of Edinburgh, Edinburgh, UK

Thanks for the extra information, and congratulations on a useful article. JAD.

Competing Interests: No competing interests were disclosed.

Reviewer Expertise: Tissue engineering \& Synthetic Biology (but my reservations, which are purely about more methodological details being needed in places, do not depend on any deep expertise). 


\section{I confirm that I have read this submission and believe that I have an appropriate level of expertise to confirm that it is of an acceptable scientific standard.}

\section{Version 1}

Reviewer Report 22 May 2020

\section{https://doi.org/10.5256/f1000research.21837.r62499}

(C) 2020 Pranke $\mathbf{P}$. This is an open access peer review report distributed under the terms of the Creative Commons Attribution License, which permits unrestricted use, distribution, and reproduction in any medium, provided the original work is properly cited.

\section{Patricia Pranke}

Hematology and Stem Cell Laboratory, Faculty of Pharmacy, Universidade Federal do Rio Grande do Sul (UFRGS), Porto Alegre, Brazil

The article analyzes the effect of the bio-electrospray (BES) technique on human neural stem cells (hNSCs). Although the BES provoked a decrease in hNSC metabolic activity, there was no increase in hNSC death. The differentiated assays were also successful, showing that the BES did not adversely affect the differentiation capacity of the hNSCs or their gene expression. The figures are very illustrative and very well executed.

Please correct VERY instead of "VEY well and could...." In the line 1 on the second column of the Introduction.

The paper is very well written and it could probably be indexed without additional revision. Having said that, there are a few minor errors which could be adjusted, but they are small details. I have 6 more additional examples if you need them.

In the Abstract:

"Bio-electrospray (BES) is a jet based" - change to "Bio-electrospraying (BSE)"

"...has the ability to form..." - "..has the ability of forming..."

“...different hNSC lines..' - '...a number of hNSC lines..."

"...from which cells recovered..." - "...from which the cells recovered..."

"...as efficiently as controls..." - "...as efficiently as the controls..."

"...and oligodentocytes as shown by..." - "...and oligodentrocytes, as shown by..."

Is the work clearly and accurately presented and does it cite the current literature? 
Yes

Is the study design appropriate and is the work technically sound?

Yes

Are sufficient details of methods and analysis provided to allow replication by others? Yes

If applicable, is the statistical analysis and its interpretation appropriate?

Yes

Are all the source data underlying the results available to ensure full reproducibility? Yes

Are the conclusions drawn adequately supported by the results?

Yes

Competing Interests: No competing interests were disclosed.

Reviewer Expertise: Tissue engineering and regenerative medicine - area of stem cell and nanotechnology (electrospinning mainly)

I confirm that I have read this submission and believe that I have an appropriate level of expertise to confirm that it is of an acceptable scientific standard.

Author Response ( F1000Research Advisory Board Member ) 15 Jun 2020

Patrizia Ferretti, UCL Great Ormond Street Institute of Child Health, University College London, London, UK

We thank you the Reviewer for their kind comments and useful suggestion which we have incorporated in the revised version of the manuscript.

Competing Interests: No conflict of interest.

Reviewer Report 11 May 2020

https://doi.org/10.5256/f1000research.21837.r62498

(C) 2020 Xie J. This is an open access peer review report distributed under the terms of the Creative Commons Attribution License, which permits unrestricted use, distribution, and reproduction in any medium, provided the original work is properly cited.

? Jingwei Xie

Department of Surgery-Transplant and Mary and Dick Holland Regenerative Medicine Program, 
College of Medicine, University of Nebraska Medical Center, Omaha, NE, USA

This work reports bioelectrospray of human neural stem cells and examines the survival, growth, and differentiation after bioelectrospray. This is an interesting work as bioelectrospray could be used to deposit human neural stem cells to form patterns for forming and studying complex neural tissue constructs. Overall, this work is satisfactory. However, authors should provide details of the bioelectrospray process. For example, how long for the process? In addition, the flow rate $250 \mathrm{ml} / \mathrm{h}$ seems too high. Please double check.

Is the work clearly and accurately presented and does it cite the current literature? Yes

Is the study design appropriate and is the work technically sound?

Yes

Are sufficient details of methods and analysis provided to allow replication by others? Yes

If applicable, is the statistical analysis and its interpretation appropriate? Yes

Are all the source data underlying the results available to ensure full reproducibility? No source data required

Are the conclusions drawn adequately supported by the results? Yes

Competing Interests: No competing interests were disclosed.

Reviewer Expertise: Electrospray, Biomaterials, Tissue Regeneration

I confirm that I have read this submission and believe that I have an appropriate level of expertise to confirm that it is of an acceptable scientific standard, however I have significant reservations, as outlined above.

Author Response ( F1000Research Advisory Board Member ) 15 Jun 2020

Patrizia Ferretti, UCL Great Ormond Street Institute of Child Health, University College London, London, UK

We thank the Reviewer for this comment. It should be noted that this study focused on the initial crucial question concerning cell viability and maintenance of differentiation capability after bioelectrospraying rather than on the formation of the stable cone jet mode needed to obtain micro to nano-sized droplets. Hence, a high flow rate was used to evaluate cell viability when exposed to the high voltage and needle constraints of BES. Because of the high flow rate, cells were subjected to the voltage for less than a minute. This study provides the foundation for the use of hNSCs to refine the conditions for achieving a stable 
cone jet mode. To this purpose, flow rate adjustments, single or coaxial needle arrangement, and liquid properties mentioned will need to be analysed.

Competing Interests: No conflict of interest.

Reviewer Report 01 May 2020

https://doi.org/10.5256/f1000research.21837.r62497

(C) 2020 Davies J. This is an open access peer review report distributed under the terms of the Creative Commons Attribution License, which permits unrestricted use, distribution, and reproduction in any medium, provided the original work is properly cited.

\section{Jamie A. Davies}

Deanery of Biomedical Sciences, University of Edinburgh, Edinburgh, UK

Overall, this study is a report of useful, incremental research. Previous reports, including some by the same lead author, have shown that a range of mammalian cells tolerate BES well. This report effectively says "and so do hNSCs". Not a surprise (there was no obvious reason that the wouldn't) but a useful thing to know nevertheless.

Specific comments:

I liked your use of both transported and un-transported controls.

In the methods, it would be helpful to have catalogue numbers of all of the biologics (growth factors etc), because these can be purchased in subtly different forms (native, recombinant, etc). Knowing the exact one helps the cause of reproducibility.

In the first paragraph of the Introduction, 3 lines up, it would be helpful to know what BES conditions can be altered (otherwise it is hard to make the comparison with the less advantageous techniques mentioned in the subsequent sentence).

Methods, $2^{\text {nd }}$ paragraph, last line - what is N2? If it is the culture supplement that ThermoFisher (and maybe others) sell, please give a reference or at least an explanation.

Can you say more about the needle? (eg supplier code) and the field strength (you keep quoting $10 \mathrm{kV}$, but not the distance over which this potential exists). Again, this is for reproducibility.

It is also critical that you provide more information about the BES setup (distances etc); assuming this is one you have described in previous publications, you can just cite these publications. But without this information, nobody could reproduce this work.

Strictly, the whole manuscript requires careful copy-editing to remove minor errors of punctuation and syntax, but these errors do not make the existing manuscript too hard to understand. 
Is the work clearly and accurately presented and does it cite the current literature? Yes

Is the study design appropriate and is the work technically sound?

Yes

Are sufficient details of methods and analysis provided to allow replication by others? No

If applicable, is the statistical analysis and its interpretation appropriate? Yes

Are all the source data underlying the results available to ensure full reproducibility? Yes

Are the conclusions drawn adequately supported by the results?

Yes

Competing Interests: No competing interests were disclosed.

Reviewer Expertise: Tissue engineering \& Synthetic Biology (but my reservations, which are purely about more methodological details being needed in places, do not depend on any deep expertise).

I confirm that I have read this submission and believe that I have an appropriate level of expertise to confirm that it is of an acceptable scientific standard, however I have significant reservations, as outlined above.

Author Response ( F1000Research Advisory Board Member ) 15 Jun 2020

Patrizia Ferretti, UCL Great Ormond Street Institute of Child Health, University College London, London, UK

We are grateful to the Reviewer for his helpful comments. "In the methods, it would be helpful to have catalogue numbers of all of the biologics (growth factors etc), because these can be purchased in subtly different forms (native, recombinant, etc). Knowing the exact one helps the cause of reproducibility."

This has been included, but please note that full information about a couple of reagents is still missing because we do not have access to it due to the current lockdown to control the Covid-19 pandemic.

"In the first paragraph of the Introduction, 3 lines up, it would be helpful to know what BES conditions can be altered (otherwise it is hard to make the comparison with the less advantageous techniques mentioned in the subsequent sentence)."

The configuration needed to obtain micro to nano-sized droplets, and a near mono- 
distribution can be achieved by adjusting BES conditions to obtain a stable cone jet mode. The primary conditions to consider are viscosity and electrical conductivity of the sprayed liquid. Ideally, the cell-laden suspension should have high viscosity and low electrical conductivity. A coaxial arrangement with an outer needle carrying an encapsulating biomaterial and an inner needle carrying the cells in suspension could also be considered (Jayasinghe and Townsend-Nicholson, 2006). This has now been specified.

"Can you say more about the needle? (eg supplier code) and the field strength (you keep quoting $10 \mathrm{kV}$, but not the distance over which this potential exists). Again, this is for reproducibility. It is also critical that you provide more information about the BES setup (distances etc); assuming this is one you have described in previous publications, you can just cite these publications. But without this information, nobody could reproduce this work."

The needle used in these studies are similar to those used in our previous studies $[x]$, and is a standard straight cut hypodermic needle made of stainless steel. The field strength was $0.2 \mathrm{kv} / \mathrm{mm}(10 \mathrm{kv}$ over $50 \mathrm{~mm}$ ) and a reference has been added: O'Neill HC, Maalouf WE, Harper JC, Jayasinghe SN. Bio-electrosprayed human sperm remain viable. Materials Today. 2019; 1;31:21-30.“

Competing Interests: No competoing interest.

The benefits of publishing with F1000Research:

- Your article is published within days, with no editorial bias

- You can publish traditional articles, null/negative results, case reports, data notes and more

- The peer review process is transparent and collaborative

- Your article is indexed in PubMed after passing peer review

- Dedicated customer support at every stage

For pre-submission enquiries, contact research@f1000.com 